\title{
EDUCAÇÃO MORAL OU EDUCAÇÃO ESTÉTICA? SOBRE SCHILLER E FICHTE
}

\author{
Moral education or aesthetic education? On Schiller and Fichte
}

Ricardo Barbosa

UERJ

Resumo: $O$ artigo discute uma tese de Xavier Léon sobre a atitude de Schiller em relação a Fichte e procura mostrar sob quais condições as cartas Sobre a educação estética do homem (1794-95) podem ser lidas como uma resposta a Algumas preleções sobre a destinação do erudito (1794).

Palavras-chave: Schiller, Fichte, educação estética, educação moral, modernidade.

Abstract: The article discusses a thesis of Xavier Léon about Schiller's attitude towards Fichte and sought to show under which conditions the letters On the Aesthetic Education of Man (1794-95) can be read as an answer to Some Lectures concerning the Scholar's Vocation (1794).

Keywords: Schiller, Fichte, aesthetic education, moral education. modernity.

\begin{abstract}
"Todas as coisas que de algum modo possam ocorrer no fenômeno são pensáveis sob quatro relações diferentes. Uma coisa pode referir-se imediatamente a nosso estado sensível (nossa existência e bem-estar): esta é a sua índole física. Ela pode, também, referir-se a nosso entendimento, possibilitando-nos conhecimento: esta é sua índole lógica. Ela pode, ainda, referir-se a nossa vontade e ser considerada como objeto de escolha para um ser racional: esta é sua índole moral. Ou, finalmente, ela pode referir-se ao todo de nossas diversas faculdades sem ser objeto determinado para nenhuma isolada dentre elas: esta é sua índole estética. (...) Existe, assim, uma educação para a saúde, uma educação do pensamento, uma educação para a moralidade, uma educação para o gosto e a beleza. Esta tem por fim desenvolver em máxima harmonia o todo de nossas faculdades sensíveis e espirituais."
\end{abstract}

F. Schiller ${ }^{1}$

\footnotetext{
${ }^{1}$ SCHILLER, Friedrich. A educação estética do homem. Numa série de cartas. Trad. Roberto Schwarz e Márcio Suzuki. São Paulo: Iluminuras, 1990, p. 107, nota. - Para as citações seguintes, EE.
} 
A assimilação da Wissenschaftslehre por Schiller, decisiva para o estabelecimento do seu "idealismo estético", é um dos tópicos mais polêmicos desde que se iniciaram os estudos sobre as relações entre Schiller e Fichte. Xavier Léon, o autor de um dos primeiros trabalhos substanciais sobre o tema, ${ }^{2}$ não hesitou em afirmar que as cartas Sobre a educação estética do homem (1794-95) teriam sido escritas em resposta a Algumas preleções sobre a destinação do erudito (1794). Começaremos pelo exame da tese de Léon - muito provocante, embora inaceitável nos termos em que foi defendida (I). Este exame nos permitirá colocar em evidência as semelhanças entre os diagnósticos das patologias da modernidade formulados por Fichte e Schiller e as diferenças entre as terapias prescritas por ambos: a educação moral, tal como Fichte a sustentou em Algumas preleções sobre a destinação do erudito (II), e a educação estética, sobre a qual Schiller escreveu longamente em Die Horen (III).

Léon identificou a influência de Fichte já numa longa carta de Schiller a Körner, de 25 de outubro de 1794, na qual apresenta algumas das principais conclusões da teoria da beleza que vinha desenvolvendo desde as suas preleções sobre estética (1792-93) e que se encontra exposta nas cartas a Körner sobre Kallias (de janeiro-fevereiro de 1793), nas cartas ao Príncipe de Augustenburg (de fevereiro a dezembro de 1793) e em Sobre graça e dignidade (1793). Schiller se dizia convencido de que todas as dissensões sobre a beleza presentes entre indivíduos em geral de acordo quanto ao modo de sentir e aos princípios deviam-se a que tinham por base um conceito empírico da beleza. Assim, seriam inevitáveis os conflitos entre as representações do belo e a experiência, "pois a experiência propriamente não apresenta de modo algum a ideia do belo, ou, antes, porque o que se sente habitualmente como belo não é de modo algum o belo. $O$ belo não é um conceito da experiência, e sim antes um imperativo. Ele é certamente objetivo, mas apenas como

\footnotetext{
${ }^{2}$ LÉON, Xavier "Schiller et Fichte". In: Études sur Schiller. Paris: F. Alcan, 1905, pp. 41-93. O trabalho foi posteriormente incorporado pelo autor - com pequenas modificações e reduções - à sua obra Fichte et son Temps. Paris: Armand Colin, 1922, vol. 1, pp. 339-62.
} 
uma tarefa necessária para a natureza sensível e racional; na experiência efetiva, no entanto, ela permanece habitualmente não satisfeita, e se um objeto pode ainda assim ser belo, então o entendimento antecipador faz dele momentaneamente um objeto perfeito, ou a sensibilidade antecipadora faz dele um objeto meramente agradável. É algo inteiramente subjetivo se sentimos o belo como belo; mas isso deveria ser objetivo."3

Para Léon, saltam aos olhos "a analogia entre essa visão de Schiller e a de Fichte", a "quase identidade de suas expressões", pois conceber a beleza como um imperativo significa torná-la num ideal, entendido nos termos da Wissenschaftslehre, ou seja, como uma tarefa a ser realizada. "Como essa visão se encontra aqui pela primeira vez em Schiller, é difícil não admitir a influência exercida desde o primeiro encontro pelo jovem filósofo sobre o espírito do poeta." ${ }^{4}$ De resto, as cartas sobre a educação estética atestariam e aprofundariam essa influência mediante o argumento de que a perfeita ação recíproca entre os impulsos sensível e formal é a própria ideia da humanidade do homem e, como tal, uma tarefa da razão. "É a Ideia de sua humanidade, no sentido mais próprio da palavra, um infinito, portanto, do qual pode aproximar-se mais e mais no curso do tempo sem jamais alcançá-lo."6 A plena realização da humanidade do homem, sendo uma tarefa da razão, seria portanto uma "tarefa infinita", no sentido que Fichte dera a esta expressão em suas preleções sobre a destinação do erudito, retomado aqui por Schiller. - Surge assim uma questão inevitável, como escreve Léon: “Com efeito, podemos perguntar, lendo as Cartas sobre a educação estética da humanidade, se Schiller não sofreu a influência de Fichte como sofreu a de Kant, e se ele não deve ao herdeiro da filosofia crítica ao menos tanto quanto ao seu fundador."7

Léon acreditava que a teoria dos impulsos seria "uma imitação" da teoria de Fichte e que toda a dedução do estado estético como um estado de jogo (cartas 19 a

\footnotetext{
${ }^{3}$ Schillers Werke. Nationalausgabe. 27. Bd.: Briefwechsel: Schillers Briefe 1794-1795. Edição de Günther Schulz. Weimar: Hermann Böhlaus Nachfolger, 1958, pp. 70-1. - As demais citações da Nationalausgabe serão referidas pela abreviatura $N A$, seguida pelo número do volume e da página.

${ }^{4}$ LÉON, Xavier. "Schiller et Fichte", p. 56.

${ }^{5}$ Ibid., pp. 60-1.

${ }^{6} E E, 77$.

${ }^{7}$ LÉON, Xavier. "Schiller et Fichte", pp. 56-7.
} 
24) remontaria à Grundlage, à síntese E dos "Fundamentos do saber teórico", pela qual Fichte "descobre na atividade independente da imaginação o traço de união entre as duas atividades opostas do Eu, a intermediária entre o entendimento finito (sensível), que é o elemento material, real, e o elemento infinito, que é o elemento formal, ideal, o meio onde se realiza o ideal." ${ }^{8}$ - No entanto, apesar de tais semelhanças e proximidades, nada disso seria tão importante como parece: afinal, Schiller não teria sofrido "a disciplina da doutrina da ciência"9 nem suas cartas sobre a educação estética teriam acrescentado algo de novo ao que já havia pensado. De acordo com Léon, a teoria do belo contida nas cartas resume-se a três teses: 1) que existem dois impulsos fundamentais; 2) que esses impulsos não são necessariamente contraditórios e, por isso, podem ser harmonizados; 3) que existe um impulso intermediário capaz de fazê-lo, o impulso lúdico, cuja expressão mais alta é o estado estético. Essa teoria não representaria nenhuma novidade porque o problema da oposição dos impulsos já estava presente na dissertação de conclusão do curso de medicina, Ensaio sobre a conexão da natureza animal do homem com a sua natureza espiritual (1780), na qual Schiller advoga a existência de uma Mittelkraft, uma força mediadora desta dupla natureza, retornando "quase a cada página" das cartas a Körner sobre o projeto de Kallias. Além disso, a visão da arte como harmonizadora e unificadora da natureza mista do homem remontava ao poema "Os artistas", como o próprio Schiller dissera a Körner numa carta de 12 de janeiro de 1789, e todo o projeto de Kallias não seria outra coisa senão uma tentativa de deduzir esse "meio", esse ponto de harmonização da natureza humana, também referido em Sobre graça e dignidade, o qual seria finalmente definido nas cartas sobre a educação estética como o impulso lúdico e o estado estético.

Léon usa a expressão "teoria da beleza" numa acepção ampla, de modo que poderia se referir, com o mesmo efeito, à "estética" de Schiller, embora ela não se deixe reduzir àquelas três teses. Ocorre que o próprio Schiller, na medida mesma em que desenvolvia suas reflexões e as expunha ora a Körner, ora ao Príncipe de

\footnotetext{
${ }^{8}$ Idem, Fichte et son Temps, vol. 1, p. 346.

${ }^{9}$ Ibid.
} 
Augustenburg, ora em artigos e, claro, em suas preleções, fazia uma distinção entre o que planejara para Kallias e para a edição de sua correspondência com o Príncipe. Schiller já havia começado a trabalhar nessa edição quando pediu a Körner que lhe enviasse as cartas que lhe escrevera em janeiro e fevereiro de 1793 sobre Kallias, pois precisava com urgência desse material. Além disso, dizia já ter pronta uma parte do texto, "onde considero o belo e o gosto apenas em sua influência sobre os homens e a sociedade, e onde as idéias mais ricas de 'Os artistas' estão filosoficamente tratadas." ${ }^{10} \mathrm{Em} 12$ de setembro de 1794, Körner era informado sobre o estado em que se encontrava esse trabalho: "Elaboro agora minha correspondência com o Príncipe de Augustenburg, que Ihe envio certamente em três semanas. Ela constituirá um todo, sob o título: Sobre a educação estética do homem, e assim será independente de minha própria teoria do belo, embora possa muito bem preparar para isto. Ela me proporciona de novo muita alegria, e procuro conferir-lhe toda perfeição possível." ${ }^{11}$

Como se vê, Schiller distinguia entre a sua teoria do belo, tomada em sentido estrito, e suas reflexões sobre a educação estética - ou seja, entre a elucidação estritamente conceitual da beleza, como a encontramos em Kallias, e o problema dos efeitos formativos do belo e do gosto, tema de sua correspondência com o Príncipe. Que as reflexões sobre esse problema pudessem servir de preparativo para a teoria da beleza é algo que se explica talvez pelo fato de que, naquele momento, Schiller ainda não tivesse estabelecido com suficiente clareza os nexos entre os dois planos. Assim, por exemplo, numa carta a Erhard, de 26 de outubro desse ano, ele se dizia ainda "muito ocupado com a analítica do belo e com uma espécie de filosofia elementar para as belas artes, que consistirá no objeto principal de minhas contribuições para Die Horen."12 Uma distinção tão nítida entre a "teoria do belo" e uma reflexão sobre "o belo e o gosto meramente em sua influência sobre o homem e a sociedade", ao ponto de torná-las independentes entre si, perde a sua sustentação quanto mais Schiller avança na reelaboração de sua correspondência com o Príncipe, ou seja, quanto mais a

\footnotetext{
${ }^{10}$ NA 26, 336. - Schillers Werke. Nationalausgabe. 26. Bd: Briefwechsel: Schillers Briefe 1. 3. 1790 - 17. 5. 1794. Weimar: Hermann Böhlaus Nachfolger, 1992. Cf. tb. carta a Körner de 3 de fevereiro de 1794, NA 26, 341-6.

${ }^{11} N A 27,46$.

${ }^{12}$ NA 26, 72-3.
} 
analítica antropológica - sua "Elementarphilosophie para as belas artes" - abre o caminho para a fundamentação estética do idealismo transcendental. ${ }^{13}$ Sob esse aspecto, Léon tem razão em se referir amplamente à "teoria da beleza" de Schiller. Por outro lado, Schiller poderia estar aludindo justamente à temática da segunda série das cartas (10 a 16), que seria publicada em fevereiro de 1795 . Nesse sentido, toda a posição do problema contida nas primeiras cartas, bem como o diagnóstico da modernidade a que ela dá ensejo, serviria de preparativo para a dedução do conceito racional puro da beleza, cerne da segunda série das cartas - uma dedução que, por sua vez, sustentar-se-ia a si mesma de tal modo que seria perfeitamente independente das reflexões sobre a educação estética e o seu significado no contexto histórico-político que as inspiraram.

A tese de Léon não só ignora estes desenvolvimentos como também não tem o amparo das fontes; pois, além de não levar em conta a correspondência com o Príncipe de Augustenburg, em Kallias ou em qualquer outro escrito anterior às cartas sobre a educação estética não há nenhuma referência a um impulso lúdico, capaz de harmonizar a natureza mista do homem. No entanto, Léon afirma que "a existência de um impulso intermediário, o impulso lúdico, que torna esta harmonia possível porque une em si as duas formas da atividade humana, a forma sensível e a forma inteligível, a mudança e a identidade, o finito e o infinito, é exatamente o 'meio' onde, segundo o mesmo Kallias, se encontram e se determinam reciprocamente, sem se contradizer e sem se destruir, a natureza e a liberdade; é o meio que constitui a atividade estética, definida precisamente não como uma atividade determinante real, mas como liberdade na aparência, ou seja, como atividade lúdica." ${ }^{14}$

O problema está nesse "ou seja", pois Léon simplesmente identifica o conceito da beleza como liberdade na aparência com o de jogo, como se Schiller já tivesse estabelecido essa identidade nas cartas sobre Kallias. Ocorre que essas cartas não oferecem um único ponto de sustentação para essa tese: nelas a palavra jogo aparece apenas duas vezes e nunca no sentido que Schiller Ihe atribui em Sobre a

13 BARBOSA, Ricardo. "O 'idealismo estético' e o factum da beleza. Schiller como filósofo". In: idem, Limites do belo. Estudos sobre a estética de Friedrich Schiller. Belo Horizonte: Relicário, 2015, pp. 135-84. ${ }^{14}$ LÉON, Xavier. Fichte et son Temps, vol. 1, p. 347. 
educação estética do homem. E se nos voltarmos para a primeira versão dessa obra, ou seja, a correspondência com o Príncipe de Augustenburg durante 1793 (portanto, antes mesmo que tivesse ocorrido a Fichte o insight que o levou à Wissenschaftslehre), veremos que a palavra jogo aparece seis vezes, sendo em geral empregada no sentido kantiano do jogo das faculdades, contra o qual Schiller se volta em sua busca de um princípio objetivo do belo e do gosto, como no seguinte passo: “Quando reflito sobre o vínculo do sentimento do belo e do grande com a parte mais nobre do nosso ser, é-me impossível considerá-lo como um jogo apenas subjetivo da faculdade de sentir, o qual não é capaz de outra coisa senão de regras empíricas. Como a verdade e o direito, parece-me que também a beleza tem de repousar sobre fundamentos eternos, e as leis originais da razão têm de ser também as leis do gosto." ${ }^{15}$ Como o próprio Schiller dissera a Körner, o que o movia era a intenção de desenvolver e fundamentar filosoficamente a ideia central já exposta em "Os artistas". E se Léon chamava a atenção para a importância desse poema na elaboração da estética de Schiller, o fazia corretamente, mesmo ignorando a correspondência com o Príncipe de Augustenburg, de resto já parcialmente publicada à época em que escreveu seu importante estudo sobre Schiller e Fichte.

Contudo, creio que a tese de Léon, segundo a qual as cartas sobre a educação estética "não acrescentam nada" ao que Schiller pensara até então, é inaceitável porque também minimiza o impacto da influência de Fichte, que deu a Schiller justamente o que esse mais precisava: uma orientação metodológica segura em sua tentativa de encaminhar a teoria do belo, do gosto e das artes pela "via transcendental". Essa orientação metodológica se expressa antes de tudo no primado do ponto de vista antropológico, que Schiller encontrara claramente exposto na primeira preleção de Fichte sobre a destinação do erudito. Sob esse aspecto, a tese de Léon é sutilmente dissonante. "Se não se pode negar que a exposição nova, sob a qual Schiller apresenta sua teoria da beleza nas cartas sobre a educação estética, as expressões que ele emprega, o método e a natureza de suas deduções sejam

${ }^{15}$ SCHILLER, Friedrich. Cultura estética e liberdade. Cartas ao Príncipe de Augustenburg, fevereirodezembro de 1793. Organização, tradução e introdução de Ricardo Barbosa. São Paulo: Hedra, 2009, pp. 57-8 / NA 26, 185. 
empréstimos à doutrina da ciência, é impossível afirmar que a influência da doutrina da ciência tenha modificado no que quer que seja as ideias de Schiller. O que é preciso ver nesses empréstimos não é sem dúvida uma concessão à voga reinante, que, na Jena de então, disseminava todas as fórmulas de Fichte - uma tal concessão não estaria bem de acordo com o caráter de Schiller - ou uma homenagem prestada ao valor da 'nova filosofia'; o que seria bem mais provavelmente um simples meio polêmico, se é exato que as cartas sobre a educação estética não são, no fundo, senão uma resposta às teorias de Fichte." 16 - "Um exame mais aprofundado nos permite afirmar sem hesitação: as Cartas sobre a educação estética do homem respondem às famosas conferências de domingo sobre a destinação do erudito."17 - Se é assim, então já não se pode dizer simplesmente que as cartas sobre a educação estética "não acrescentam nada" ao que Schiller já havia pensado e escrito. O "idealismo estético" de Schiller, sua filosofia madura, é precisamente o que as cartas "acrescentam" ao que ele "já havia pensado e escrito"... ${ }^{18}$

Mas se de fato é possível ler as cartas como uma resposta às preleções de Fichte (e Léon oferece argumentos convincentes nesse sentido), então isto é o bastante para tornar secundária toda especulação sobre propósitos e intenções subjetivos, pois o que permanece para além disso é sempre a questão sobre como determinados textos e argumentos se comportam objetivamente como respostas a outros textos e argumentos. E se Schiller deve tanto ao fundador quanto ao herdeiro da filosofia crítica, é igualmente verdadeiro que ele não deve menos a si mesmo, ao seu trato espontâneo e direto com os problemas estéticos suscitados pela sua própria produção artística bem como às suas convicções políticas.

\footnotetext{
${ }^{16}$ LÉON, Xavier. Fichte et son Temps, vol. 1, p. 347. No ensaio "Schiller et Fichte", Léon formula este argumento do seguinte modo: "Segue-se das considerações precedentes que a teoria do belo nas Cartas sobre a educação estética é exatamente a que Schiller expôs a Körner em 1792 e em 1793; e se somos então forçados a reconhecer na forma nova pela qual Schiller apresenta sua teoria, na escolha de suas expressões, na natureza das suas deduções, em toda dialética que ele emprega agora um inegável empréstimo à Doutrina da ciência, contudo podemos afirmar que a influência de Fichte não modificou em nada as idéias essenciais da estética schilleriana. É preciso ir mais longe; e pode-se mostrar que as Cartas sobre a educação estética, longe de serem uma adesão às idéias de Fichte, são, no fundo, dirigidas contra elas." Cf. p. 68.

${ }^{17}$ Idem, Fichte et son Temps, vol. 1, p. 348.

${ }^{18}$ Cf. BARBOSA, Ricardo. "O 'idealismo estético' e o factum da beleza. Schiller como filósofo". In: idem, Limites do belo. Estudos sobre a estética de Friedrich Schiller.
} 
Para fundamentar sua leitura, Léon reconstrói o jogo de afinidades e diferenças entre as preleções sobre o erudito e as cartas sobre a educação estética. Mostra assim que Schiller e Fichte estão de acordo no diagnóstico da época, que deploram sua debilidade moral, projetando a partir dela - e contra ela - a imagem de uma humanidade regenerada. "A preocupação que domina então o pensamento de Fichte, a reforma social e moral dos homens pelo retorno à sua verdadeira destinação, é também a preocupação que inspira a Schiller o plano de suas Cartas; as cartas II a X não deixam subsistir nenhuma dúvida a respeito disso." ${ }^{19}$ - No entanto, o princípio da divergência básica entre ambos se deixa notar já no próprio diagnóstico da época, pois é na crítica ao purismo racionalista que Schiller lapida os conceitos com as quais elabora uma crítica da modernidade mais sutil que a de Fichte. Vejamos primeiro as teses de Fichte.

\section{II}

Algumas preleções sobre a destinação do erudito restitui integralmente o conteúdo das cinco primeiras seções do curso público oferecido por Fichte na Universidade de Jena no semestre de verão de 1794. A destinação do erudito é diretamente tratada somente na quarta preleção. Fichte prepara metodicamente sua abordagem perguntando inicialmente "Sobre a destinação do homem em si" (1a preleção), "Sobre a destinação do homem na sociedade" (2a preleção) e "Sobre a diversidade das categorias na sociedade" (3a preleção). Afinal, diz Fichte, o erudito é não só um membro da sociedade como também de uma categoria social específica. A escolha de uma categoria deve ser uma escolha livre; portanto, toda coação - seja para que um indivíduo ingresse numa categoria, seja para que a deixe - resulta aqui em injustiça, pois ele terá sido tratado como uma "ferramenta" social, e não como "um membro da sociedade", "um livre colaborador no nosso grande plano". ${ }^{20}$ Por

\footnotetext{
${ }^{19}$ LÉON, Xavier. Fichte et son Temps, vol. 1, p. 348.

${ }^{20}$ FICHTE, Johann Gottlieb. Einige Vorlesungen über die Bestimmung des Gelehrten. In: J. G. FichteGesamtausgabe der Bayerischen Akademie der Wissenschaften, 1/3: Werke 1794-1796. Edição de Reinhard Lauth e Hans Jacob, com a colaboração de Richard Schottky. Stuttgart-Bad Cannstatt: Frommann-Holzboog, 1966, p. 48. Para as citações seguintes, BG. Edição brasileira: FICHTE, Johann Gottlieb. O destino do erudito. Tradução e posfácio de R. Barbosa. São Paulo Hedra, 2014.
} 
outro lado, o homem tem o dever de colocar sua formação a serviço da sociedade, pois foi graças ao "trabalho da sociedade" que pôde adquiri-la: "Cada um tem o dever de não apenas querer ser útil em geral à sociedade, mas também de dirigir todos os seus esforços, o melhor que o saiba, para o fim último da sociedade, para enobrecer cada vez mais o gênero humano, isto é, torná-lo cada vez mais livre da coerção da natureza, cada vez mais independente e autoativo - e assim, através dessa nova desigualdade, surge uma nova igualdade: um progresso uniforme da cultura (Cultur) em todos os indivíduos." ${ }^{21}$

Naturalmente, Fichte não afirma que tudo se passa desse modo, e sim que tudo deveria ocorrer assim, segundo conceitos práticos. O que cabe então ao erudito e à sua categoria na realização dessa meta? Se, à luz dos resultados anteriores, perguntarmos sobre a perfeição ou a imperfeição de uma sociedade, a resposta a essa pergunta dependerá da resposta a uma outra: "cuidou-se, na sociedade dada, do desenvolvimento e da satisfação de todos os carecimentos e, na verdade, do desenvolvimento e da satisfação uniformes de todos? Se se cuidasse disso, a sociedade seria perfeita enquanto sociedade, o que não quer dizer que ela teria alcançado a sua meta, o que, segundo nossas considerações anteriores, é impossível, e sim que estaria de tal modo instituída que teria de se aproximar necessariamente cada vez mais da sua meta. Mas caso não se tivesse cuidado disso, ela em verdade poderia, por um acaso feliz, avançar no caminho da cultura, mas nunca poder-se-ia contar seguramente com isso; ela poderia igualmente, por um acaso infeliz, regredir." 22

O igual desenvolvimento de todas as disposições humanas pressupõe o conhecimento dessas disposições. Esse conhecimento, por sua vez, está igualmente fundado numa disposição que, como qualquer outra, deve ser cultivada e desenvolvida: o "impulso para saber, e, particularmente, para saber o que the é necessário. Mas o desenvolvimento dessa disposição exige todo o tempo e todas as forças de um homem. Se existe algum carecimento comum que exige instantemente

\footnotetext{
${ }^{21} B G, 49$.

${ }^{22} B G, 52$.
} 
que uma categoria particular se dedique à sua satisfação, então é esse." ${ }^{23} \mathrm{O}$ primeiro tipo de conhecimento - o das necessidades - é o conhecimento filosófico, pois está fundado na razão. O segundo tipo - o dos meios - é o conhecimento históricofilosófico, pois não pode prescindir do recurso à experiência. Ambos os tipos devem se unir num terceiro, pois só assim é possível determinar o grau de desenvolvimento cultural de uma sociedade, conhecer suas necessidades atuais e os meios para satisfazê-las na direção de sua meta. Esse conhecimento é o conhecimento histórico propriamente dito. A reunião desses três tipos de conhecimento forma o que Fichte chama "erudição", Gelehrsamkeit - e aquele que dedica sua vida a isso é propriamente o erudito, o Gelehrte. A impossibilidade de abarcar ao mesmo tempo todos esses conhecimentos não deve porém resultar na renúncia a considerar o que quer que seja segundo esses três aspectos. Por isso o estudo da filosofia não pode dispensar a aquisição de conhecimentos empíricos. Se a meta de todos esses conhecimentos é promover o desenvolvimento uniforme e progressivo de todas as disposições humanas, então a destinação do erudito é "a suprema inspeção do progresso efetivo do gênero humano em geral e a contínua promoção desse progresso." 24

A ciência é parte da cultura humana e precisa ser desenvolvida em todos os seus ramos com vista ao desenvolvimento de todas as disposições humanas. Cabe a cada um, conforme a categoria à qual pertence, contribuir para o desenvolvimento da ciência, especialmente se se trata de um erudito. Por isso o cultivo da receptividade e da comunicação são essenciais. É pela receptividade que o erudito se coloca à altura do estado atual dos problemas e das tarefas de sua ciência, o que requer a assimilação de sua história, mas nunca em detrimento de sua independência intelectual e muito menos do impulso à comunicação com os outros. O destinatário de suas pesquisas é a sociedade; por isso deve investigar suas verdadeiras necessidades e os meios para satisfazê-las. Fichte porém não afirma que todos deveriam tornar-se eruditos, e sim que o erudito deve se esforçar para se tornar útil a todos, ou seja, a todas as categorias, classes e profissões, que devem saber contar com a habilidade e a

\footnotetext{
${ }^{23} B G, 52$.

${ }^{24} B G, 54$.
} 
probidade uns dos outros. Ao erudito cabe porém despertar e purificar em todos 0 sentimento pela verdade - e é por isso que sua a destinação deve ser a de um "mestre (Lehrer) da humanidade". ${ }^{25}$

Em sua tarefa de tornar conhecidas as necessidades humanas e os meios para satisfazê-las, o erudito deve concentrar-se especialmente nas necessidades atuais, projetando o presente no futuro, na meta final do desenvolvimento do gênero humano. E por mais clara que essa meta lhe seja, deve cuidar para não querer arrastar toda a espécie de uma só vez a ela, e sim zelar para que não se afaste dela ou retroceda. Por isso Fichte também o chama de "educador (Erzieher) da humanidade". ${ }^{26}$ Como tal, não lhe é permitido recorrer a meios violentos de persuasão nem enganar os outros, pois em ambos os casos estaria reduzindo um ser racional livre à condição de meio, de instrumento. Se a meta última da humanidade, ou seja, do indivíduo e de toda a sociedade, é "o enobrecimento moral do homem inteiro", ${ }^{27}$ recai sobre o erudito a mais alta exigência, pois a eficácia do seu ensino não deve resultar apenas de suas palavras, mas sobretudo de sua conduta, que deve ser exemplar. Entre todos os homens, "o erudito deve ser o homem moralmente melhor de sua época", ${ }^{28}$ dizia Fichte aos seus ouvintes em Jena: "Esta é a nossa destinação em comum, este é o nosso destino em comum. Um destino feliz de estar determinado pela sua vocação (Beruf) particular a fazer aquilo que teria de fazer já por causa de sua vocação geral enquanto homem - de dever dirigir seu tempo e suas forças para nada mais senão para o que, aliás, ter-se-ia de poupar tempo e energia com prudente parcimônia - de ter como trabalho, como ocupação, como única tarefa diária da sua vida o que para outros seria um doce descanso do trabalho! (...) Estou chamado a dar testemunho da verdade. Minha vida e meus destinos nada importam; já os efeitos de minha vida importam infinitamente. Sou um sacerdote da verdade. Estou a seu soldo. Obrigueime a tudo fazer, ousar e sofrer por ela. Se por sua causa devesse ser perseguido e

\footnotetext{
${ }^{25} B G, 56$.

${ }^{26} B G, 57$.

${ }^{27} B G, 57$.

${ }^{28} B G, 58$.
}

62 | Pensando - Revista de Filosofia Vol. 8, № 16, 2017

ISSN 2178-843X 
odiado, se mesmo devesse morrer ao seu serviço - o que teria feito de extraordinário, o que teria feito além do que simplesmente tinha de fazer?"29

Schiller chegou a compartilhar de um ponto de vista parcialmente semelhante, em cujo centro, porém, não figurava o erudito, mas o artista. Que se pense nos versos apologéticos de "Os artistas" ou em sua impressionante carta a Jens Baggesen, de 16 de dezembro de 1791, na qual faz um sóbrio balanço dos seus últimos dez anos de vida como escritor profissional em tensão com as exigências da arte e do mercado. Nessa carta, Schiller se refere aos deveres do escritor como "mestre dos homens". ${ }^{30}$ Em Sobre a educação estética do homem se ocupa direta e indiretamente do ethos do artista, como se lê na 9a carta, por exemplo, embora já não mais o convoque para assumir com exclusividade um papel que deve ser antes desempenhado pelo gosto e as artes em geral. Ainda assim, a proeminência pedagógica do estético se destaca e, com ela, como veremos, um traço importante das divergências entre Schiller e Fichte acerca da modernidade. Para abordá-las, consideremos a imagem da modernidade que emerge das reflexões de Fichte como um todo e, especialmente, da 5a preleção: "Exame das afirmações de Rousseau sobre a influência das artes e das ciências sobre o bem-estar da humanidade".

O título da preleção talvez possa sugerir uma ideia pouco exata do seu conteúdo, como se se tratasse de um exame das teses de Rousseau no Discurso sobre as ciências $e$ as artes. Fichte porém não se concentra em nenhum escrito em particular. Com esse exame, ele não pretendeu combater Rousseau, cuja obra admirava, mas corrigi-lo, colocá-lo em concordância consigo mesmo e compreendê-lo melhor do que ele compreendeu a si mesmo. A escolha do filósofo suíço tem uma razão muito simples: Fichte o considerava como o seu perfeito antagonista, a antítese consumada das teses que expusera nas quatro preleções anteriores. "Situei a destinação da humanidade no progresso constante da cultura e no desenvolvimento uniformemente contínuo de todas as suas disposições e carecimentos; e indiquei um lugar muito honroso na sociedade humana à categoria que deve velar pelo progresso e

\footnotetext{
${ }^{29} B G, 58$.

${ }^{30}$ NA 26, 121.
} 
a uniformidade desse desenvolvimento. Ninguém contradisse essa verdade com tanta determinação, com razões mais aparentes e com eloquência mais enérgica do que Rousseau. Para ele, o avanço da cultura (Cultur) é a única causa de toda corrupção humana. Segundo ele, não há salvação para os homens a não ser no estado de natureza; e - o que se segue de modo totalmente correto de suas proposições fundamentais - aquela categoria que mais promove o progresso da cultura, a categoria dos eruditos, é para ele não só a fonte como o ponto central de toda miséria e corrupção humanas." 31

Fichte vê em Rousseau a figura de um homem que cultivou profundamente suas disposições naturais e que, através da cultura assim adquirida, tentou convencer a humanidade de que o melhor avanço seria um retorno à natureza. Em outras palavras, Rousseau é um paradoxo vivo: alguém altamente cultivado que combate a cultura em nome do progresso da humanidade. "Portanto, ele fazia justamente o que ele mesmo condenava tão amargamente; suas ações estavam em contradição com as suas proposições fundamentais." ${ }^{32}$ O que levou Rousseau a agir foi "um impulso em seu coração", 33 mas ele não examinou esse impulso, colocando-o ao lado do que o levou ao seu erro; pois se o tivesse feito, não haveria contradição. Resolvendo-se essa contradição, acreditava Fichte, torna-se possível compreender Rousseau melhor do que ele compreendeu a si mesmo e colocá-lo em concordância consigo mesmo.

Deixo aqui de lado o argumento de Fichte sobre as razões da falta de um claro fundamento teórico no pensamento de Rousseau bem como sua viva descrição do sentimento de Rousseau perante o choque entre o mundo que imaginara e o que efetivamente encontrara, choque tanto maior porquanto o seu objeto principal fora justamente o homem de cultura, o erudito. “Ora, cheio desse amargo sentimento, Rousseau não era capaz de ver outra coisa senão o objeto que o incitara. A sensibilidade dominava. Isso era a fonte do mal. Ele queria saber suprimido apenas esse domínio da sensibilidade, a todo risco, custasse o que fosse. - O que há de espantoso se caiu no extremo oposto? - A sensibilidade não deve dominar; ela

\footnotetext{
${ }^{31} B G, 60$.

${ }^{32} B G, 61$.

${ }^{33} B G, 61$.
} 
certamente não domina quando em geral é morta, quando já não existe de modo algum ou não está desenvolvida de modo algum e não tomou força. - Daí o estado de natureza de Rousseau." ${ }^{34}$ Em outras palavras, o chamado estado de natureza é pratica e teoricamente insustentável. Fichte surpreende assim o que talvez fosse para ele a mais profunda contradição de Rousseau, quando pergunta sobre o que afinal ele queria com esse retorno à calma, à harmonia, à ausência de vícios do estado de natureza. Pois não queria ele dedicar-se assim ao enobrecimento de si mesmo e de todos? No entanto, foi o próprio desenvolvimento da cultura, que ele deplorava, que o colocou em condições de desejar para o estado de natureza o que esse estado, por si mesmo, jamais poderia proporcionar a ele e a todos. Esse é o paradoxo no qual Rousseau se encontrava, embora sem percebê-lo.

Ele queria fazer com que o homem voltasse para o estado de natureza tendo em vista, não a sua formação espiritual, e sim a independência das necessidades da sensibilidade. Mas o que ele vê no passado é precisamente o que Fichte projeta no futuro, pois a independência das necessidades da sensibilidade implica o crescente domínio da razão sobre a natureza, a progressiva liberação do homem das exigências do trabalho, a supressão de muitas necessidades e a fruição da vida sem prejuízo da virtude. "Se tal estado é pensado como ideal - em vista de que é inalcançável, como todo o ideal -, então ele é a idade de ouro da fruição dos sentidos sem trabalho corporal, que os antigos poetas descrevem. Assim, encontra-se diante de nós o que Rousseau, sob o nome de estado de natureza, e aqueles poetas, sob a denominação de idade de ouro, colocam atrás de nós."35

O que Rousseau ignora é a natureza eminentemente ativa do homem, o fato de que um tal estado depende rigorosamente do trabalho humano. "A natureza é rude e selvagem sem a mão do homem, e devia ser assim para que o homem fosse obrigado a sair do inativo estado de natureza e elaborá-la, a fim de que ele mesmo se tornasse, de um simples produto da natureza, num ser racional livre." ${ }^{36}$ Os vícios resultam da preguiça e não da necessidade, que é uma "incitação à atividade e à virtude" e a fonte

\footnotetext{
${ }^{34} B G, 63$.

${ }^{35} B G, 65$.

${ }^{36} B G, 65$.
}

65 | Pensando - Revista de Filosofia Vol. 8, № 16, 2017

ISSN 2178-843X 
de toda alegria e de todo prazer. ${ }^{37}$ O propósito da dor é justamente o de promover essa atividade em nós e nos estimular a lutar contra a imperfeição, a corrupção e a miséria. Contudo, Rousseau sofreu mais do que atuou: percebeu a miséria humana, mas não teve forças para combatê-la, colocando-se diante dos outros do mesmo modo que diante de si mesmo. Fichte o caracteriza como "o homem da sensibilidade passiva"38 - uma característica dominante também nas personagens de seus romances. "Assim, Rousseau geralmente pinta a razão em repouso, mas não em luta; ele enfraquece a sensibilidade em vez de fortalecer a razão." ${ }^{39}$ Com isso, Fichte revela o último motivo pelo qual trouxe à cena a figura de Rousseau: ele o vê como um caso altamente instrutivo, pois é o exemplo consumado do que não devemos ser. "Agir! Agir! É para isso que estamos aqui. Deveríamos nos irritar porque outros não são tão perfeitos como nós, quando somos apenas mais perfeitos? Não é justamente essa nossa maior perfeição o chamado que nos é feito no sentido de que somos nós que temos de trabalhar para o aperfeiçoamento dos outros? Alegremo-nos com o espetáculo do vasto campo que temos a elaborar! Alegremo-nos por sentir em nós a força e porque nossa tarefa é infinita!" 40

Em rigorosa concordância com o seu princípio supremo, Fichte - um erudito procura determinar a destinação do erudito. Ele se dirige ao seu público imediato, a juventude estudantil de Jena, dando testemunho de sua missão: fala abertamente como um "sacerdote da verdade", como um "mestre" e "educador" da humanidade, cuja palavra deve vir acompanhada pelo exemplo. E se ele se dirige especialmente à juventude é porque acredita que ela ainda tem chances de escapar dos descaminhos

\footnotetext{
${ }^{37} B G, 66$.

${ }^{38} B G, 67$.

${ }^{39} B G, 67$. O juízo de Schiller sobre Rousseau converge basicamente com o de Fichte. Cf. F. Schiller, Poesia ingênua e sentimental. Trad. Márcio Suzuki. São Paulo. Iluminuras, 1991, p. 54 (quando se refere indiretamente a Rousseau dirigindo-se ao "amigo sentimental da natureza") e pp. 71-2 (quando se refere diretamente a Rousseau como poeta e filósofo). Para um comentário sobre a posição de Schiller face a Rousseau, cf. SZONDI, Peter. Antike und Moderne in der Ästhetik der Goethezeit. In: idem, Poetik und Geschichtsphilosophie I. Frankfurt am Main: Suhrkamp, 1974, pp. 157-60 e HOGREBE, W. "Schiller und Fichte. Eine Skizze". In: BOLTEN, J. (org.), Schiller Briefe über die ästhetische Erziehung des Menschen. Frankfurt am Main: Suhrkamp, 1984, pp. 276-80. Sobre os diferentes "programas de educação" de Fichte e Schiller, ambos opostos a Rousseau, cf. pp. 281-2. Cf. tb. HAMBURGER, K. "Schillers ästhetisches Denken". In: SCHILLER, Friedrich. Über die ästhetische Erziehung des Menschen. Stuttgart: Reclam, 1997, p. 148.
}

${ }^{40} B G, 67-8$. 
de uma "época emasculada", ${ }^{41}$ compreendendo assim o sentido mais alto da destinação do homem, uma destinação rigorosamente social. É justamente este interesse, este propósito de influir na formação da juventude, de promover a tomada de consciência do único dever-ser capaz de honrar a destinação do homem, que faz com que a imagem da modernidade se configure aqui pelos efeitos da lente corretora desse Sollen.

Fichte vê a sociedade em geral como a ação recíproca entre os seres racionais livres e entre esses e a natureza; e a cultura como o processo da realização da razão, ou seja, do progressivo domínio humano sobre a natureza. A função do erudito tornase tanto mais importante quanto mais esse processo incrementa a especialização do trabalho. A realização da razão resulta por isso cada vez mais diferenciada, a ação recíproca dos membros da sociedade cada vez mais complexa, as relações entre as diferentes categorias sociais cada vez mais ramificadas. Assim, a imagem imediata da modernidade que se deixa ver aqui é a de uma época num crescente processo de especialização que coloca em risco as maiores exigências humanas, pois tende a promover a fragmentação ao invés da unificação, o egoísmo e não a dinâmica entre os impulsos receptivo e comunicativo, a instrumentalização de uns pelos outros no lugar do reconhecimento recíproco das liberdades. A crescente divisão e especialização do trabalho não é vista como uma ferida incurável ou a ser curada, e sim como uma necessidade histórica ancorada em condições naturais intransponíveis para o indivíduo, mas superáveis pela espécie. E o otimismo da vontade com o qual Fichte encara a tarefa do homem torna-se ainda mais evidente pelo contraste entre as suas teses e as de Rousseau. Fichte encara o presente com coragem e virilidade: não tem palavras de melancolia ou desespero, mas de confiança na destinação do homem em geral e, sobretudo, na destinação do erudito; afinal, numa época de crescente especialização cabe ao erudito a produção dos conhecimentos necessários à reconciliação do homem consigo mesmo e à sua educação moral como uma educação para a liberdade.

\footnotetext{
${ }^{41} B G, 58$.
} 
III

É compreensível que Xavier Léon tenha lido as cartas de Schiller sobre a educação estética como uma resposta a essas preleções de Fichte. No entanto, as diferenças e divergências entre Schiller e Fichte se deixam ver melhor à luz do que desde o início esteve em jogo para ambos: a correta compreensão da natureza do idealismo transcendental. A crítica de Schiller ao purismo racionalista da filosofia kantiana ${ }^{42}$ desempenha um papel decisivo nesse sentido, incidindo diretamente em seu diagnóstico da modernidade e na justificação de sua terapia: a educação estética. ${ }^{43}$

Escrevendo ainda sob o impacto do terror jacobino, que the minara a crença na revolução como via para a institucionalização da liberdade, Schiller admite que o sentido de suas "investigações sobre o belo e $a \operatorname{arte}^{44}$ não seria nada evidente em face do que polarizava as atenções dos seus contemporâneos. "Não será extemporânea a busca de um código de leis para o mundo estético, quando o moral tem interesse tão mais próximo, quando o espírito de investigação filosófica é solicitado urgentemente pelas questões do tempo a ocupar-se da maior de todas as obras de arte, a construção de uma verdadeira liberdade política?"45

Por que tanto empenho numa investigação "sobre o belo e a arte" quando "o grande destino da humanidade" era decido na "cena política"? ${ }^{46}$ Se a "revolução no mundo filosófico" operada pela crítica kantiana da razão convencera Schiller da necessidade de estendê-la à estética em busca de um fundamento objetivo para o belo, foi o fracasso da revolução no mundo político que o fez ver no gosto e na arte o medium privilegiado da formação do homem para a liberdade ${ }^{47}$ Eis a tese de Schiller: "para resolver na experiência o problema político é necessário caminhar através do estético, pois é pela beleza que se vai à liberdade." 48 A fundamentação dessa tese

\footnotetext{
42 BARBOSA, Ricardo. "A especificidade do estético e a razão prática em Schiller". In: idem, Limites do belo. Estudos sobre a estética de Friedrich Schiller, pp. 119-34.

43 BARBOSA, Ricardo. "Educação estética, educação 'sentimental'. Um estudo sobre Schiller". In: Artefilosofia, 17, 2014, pp. 146-69.

${ }^{44} E E, 23$.

${ }^{45} E E, 25$

${ }^{46} E E, 26$

${ }^{47}$ Sobre o nexo entre o estético e o político nas cartas ao Príncipe de Augustenburg, cf. BARBOSA, Ricardo. Schiller e a cultura estética. Rio de Janeiro: Jorge Zahar, 2004.

${ }^{48} E E, 26$.
} 
exigirá muitas mediações, a começar pela recapitulação dos "princípios mediante os quais a razão se guia em geral numa legislação política". ${ }^{49}$ Tais princípios dizem respeito ao direito natural e à teoria do Estado. Sua apresentação logo trará ao centro da investigação a pergunta pelo homem e as teses de Fichte sobre a destinação do homem em si e na sociedade. A aplicação dessas teses à problemática do Estado terá como resultado a transição a uma nova mediação: a da filosofia da história, de acordo com a qual Schiller formula seu diagnóstico da modernidade.

Os princípios que orientam a razão na legislação política são precisamente os que permitem a reconstrução da obra da natureza pela liberdade, ou seja, a transição da necessidade física à necessidade moral pela dissolução dos vínculos sociais meramente naturais e o seu reordenamento racional. Como essa transição não pode pôr em risco a existência física do homem em nome de sua dignidade, ela não pode basear-se nem no "caráter natural egoísta e violento do homem, que visa muito mais à destruição que à conservação da sociedade", nem no seu "caráter ético", o qual ainda deve ser criado: "Seria preciso separar, portanto, do caráter físico o arbítrio, e do moral a liberdade - seria preciso que o primeiro concordasse com leis e que o segundo dependesse de impressões; seria preciso que aquele se afastasse um pouco da matéria e este dela se aproximasse um tanto -, para engendrar um terceiro caráter, aparentado com os outros dois, que estabelecesse a passagem do domínio das simples forças para o das leis, e que, longe de impedir a evolução do caráter moral, desse à eticidade invisível o penhor dos sentidos." 50 Esse é o caráter a ser formado pela educação estética. "Uma coisa é certa: somente o predomínio de um tal caráter num povo poderá tornar inofensiva uma transformação do Estado segundo princípios morais, e somente um tal caráter poderá assegurar-lhe a duração." 51

De certo modo, a dívida de Schiller a Fichte foi paga com a tentativa de refutálo com os meios de sua própria filosofia. É o que se pode notar justamente no correr da 4⿳a carta, na sequência de uma passagem na qual Schiller se refere nominalmente pela primeira vez a Fichte. Remetendo o leitor a "uma publicação recente: Preleções

\footnotetext{
${ }^{49} E E, 26$.

${ }^{50} E E, 29$.

${ }^{51} E E, 31$.
} 
sobre a destinação do erudito, de meu amigo Fichte", Schiller Ihe atribui o crédito de ter deduzido, de maneira "bastante clara e por uma via jamais tentada", a tese segundo a qual todo ser humano "traz em si, quanto à disposição e destinação, um homem ideal e puro, e a grande tarefa de sua existência é concordar, em todas as suas modificações, com sua unidade inalterável." ${ }^{52}$ Essa é a tese central da primeira preleção de Fichte, "Sobre a destinação do homem em si", 53 e o fio condutor da analítica antropológica desenvolvida por Schiller nas cartas sobre a educação estética.

Em consonância com a sua motivação política, Schiller deriva a destinação do Estado a partir da destinação do homem. "Este homem puro, que se dá a conhecer com maior ou menor nitidez em cada sujeito, é representado pelo Estado, a forma mais objetiva e por assim dizer canônica na qual a multiplicidade dos sujeitos tenta unificar-se. É possível pensar, porém, dois modos diversos de o homem temporal coincidir com o homem ideal, e outras tantas de o Estado afirmar-se nos indivíduos: ou pela opressão do homem empírico pelo puro, quando o Estado suprime os indivíduos; ou pelo fato de o indivíduo tornar-se Estado, quando o homem no tempo se enobrece em direção ao homem na Ideia. É certo que na avaliação moral unilateral esta diferença desaparece; pois a razão se satisfaz apenas se sua lei valha incondicionalmente; na avaliação antropológica plena, porém, quando o conteúdo conta ao lado da forma e também o sentimento vivo tem a sua voz, ela será considerada tanto mais. A razão pede unidade, mas a natureza quer multiplicidade, e o homem é solicitado por ambas as legislações. A lei da primeira está gravada nele por uma consciência incorruptível; a da segunda por um sentimento inextinguível. Daí ser sempre testemunho de uma formação cultural ainda precária se o caráter ético só se afirma com o sacrifício do natural; e é ainda muito imperfeita uma constituição do Estado que só seja capaz de produzir a unidade pela supressão da multiplicidade. O Estado não deve honrar apenas o caráter objetivo e genérico nos cidadãos, mas também o

\footnotetext{
${ }^{52}$ EE, 32. - Cf. DÜSING, W. Friedrich Schiller. Über die ästhetische Erziehung des Menschen in einer Reihe von Briefen. Text, Materialien, Kommentar. Munique: Hanser, 1981, p. 151.

${ }^{53}$ A destinação última dos homens como seres racionais finitos, diz Fichte, é a "absoluta unidade, contínua identidade, inteira concordância consigo mesmos" $(B G, 30)$.
} 
subjetivo e especifico; não deve, ao ampliar o reino invisível dos costumes, despovoar o reino do fenômeno." 54

De acordo com a "avaliação antropológica plena", a harmonização da natureza pulsional humana deve ser o princípio não só de uma individuação bem conseguida (a enobrecedora síntese do "eu" como um complexo de forças sensíveis e espirituais), como também de uma socialização política tal que a síntese dos "eus" no Estado assegure a liberdade de todos e a de cada um. "O Estado deve ser uma organização que se forma por si e para si, e é justamente por isso que ele só poderá tornar-se real quando suas partes tiverem se afinado com a Ideia do todo. Por servir de representante da humanidade pura e objetiva no seio de seus cidadãos, o Estado terá de observar para com eles a mesma relação em que estes estão para si mesmos e só poderá honrar-Ihes a humanidade subjetiva no mesmo grau em que ela estiver elevada à humanidade objetiva." 55 Essa tensão entre o subjetivo e o objetivo, entre o empírico e o ideal, remete aos dois extremos que polarizam e impedem o acordo do homem consigo mesmo e o enobrecimento de sua natureza, pois a homem "pode ser oposto a si mesmo de duas maneiras: como selvagem, quando seus sentimentos imperam sobre seus princípios, ou como bárbaro, quando seus princípios destroem seus sentimentos." ${ }^{\prime 56}$

Esses dois tipos - o "selvagem" e o "bárbaro" - são essenciais à crítica da modernidade desenvolvida nas cartas seguintes; eles também já prefiguram, em sua oposição, o que pode resultar do predomínio do impulso sensível sobre o impulso formal ou desse sobre aquele. O purismo racionalista seria assim uma das formas mais refinadas de barbarismo. Contudo, o "selvagem" e o "bárbaro" desaparecem na figura do "homem cultivado" - aquele que "faz da natureza uma amiga e honra sua liberdade, na medida em que apenas põe rédeas a seu arbítrio." ${ }^{57}$ Como se lê na 13a carta, o antagonismo da natureza mista do homem, o antagonismo entre o impulso sensível e o impulso formal, não é originário. Se se admite o contrário, diz Schiller,

\footnotetext{
${ }^{54} E E, 32$.

${ }^{55} E E, 32-3$.

${ }^{56} E E, 33$.

${ }^{57} E E, 33$.
}

71 | Pensando - Revista de Filosofia Vol. 8, № 16, 2017

ISSN 2178-843X 
então esse antagonismo deve ser necessário, e a unidade da natureza humana só pode ser pensada pela subordinação do impulso sensível ao formal, ou seja, barbaramente. "Mas daí só pode surgir uniformidade, nunca harmonia, e o homem permanecerá eternamente cindido." 58 Portanto, não se trata da subordinação de um ao outro, e sim de uma harmônica "ação recíproca" (Fichte) entre ambos. É precisamente na sequência desse passo, no qual Schiller se refere nominalmente pela segunda vez a Fichte e à sua recente Fundação de toda a doutrina da ciência, que se encontra uma tese sobre a correta compreensão da natureza do idealismo transcendental - a tese segundo a qual o rigorismo e o purismo morais corresponderiam antes à letra que ao espírito da filosofia kantiana. "Numa filosofia transcendental, em que é decisivo libertar a forma do conteúdo e manter o necessário puro de todo contingente, habituamo-nos facilmente a pensar o material meramente como um empecilho e a sensibilidade numa contradição necessária com a razão, porque ela the obstrui o caminho justamente nessa operação. Um tal modo de representação não está de forma alguma no espírito do sistema kantiano, embora possa estar na letra do mesmo." 59

É precisamente esse espírito que vivifica a ideia do "homem cultivado", em contraste com o bárbaro, e o Estado da liberdade, em contraste com o da privação. "Quando, portanto, a razão transporta para a sociedade física sua unidade moral, ela não deve ferir a multiplicidade da natureza. Quando a natureza procura afirmar sua multiplicidade no edifício da sociedade, isso não deve acarretar ruptura alguma à unidade moral; a força vitoriosa repousa a igual distância da uniformidade e da confusão. É preciso, portanto, encontrar totalidade de caráter no povo, caso este deva ser capaz e digno de trocar o Estado da privação pelo Estado da liberdade." 60

Para Schiller, era justamente a ausência de um tal caráter que explicava o fracasso da Revolução Francesa e todas as mazelas da atualidade: cindida entre a "selvageria" das "classes mais baixas e numerosas" e a "lassidão" das "classes

\footnotetext{
${ }^{58} E E, 72$.

${ }^{59} E E, 72$.

${ }^{60} E E, 33-4$.
} 
civilizadas", a sociedade só se mantinha coesa pelo equilíbrio dos seus males. ${ }^{61}$ Schiller porém considerava esse estado de coisas como o resultado de um longo processo histórico. Ele o descreve mediante o contraste "entre a forma atual da humanidade e a passada, especialmente a grega" ${ }^{62}$ A história do Ocidente é vista como um processo de racionalização e especialização, pelo qual a totalidade orgânica e harmonicamente diferenciada da forma de vida grega se desfez. O traço distintivo do mundo moderno é a fragmentação em todos os planos. Enquanto o "indivíduo grego" "recebia suas forças da natureza, que tudo une", o "indivíduo moderno" "as recebe do entendimento, que tudo separa. Foi a própria cultura que abriu essa ferida na humanidade moderna. Tão logo a experiência ampliada e o pensamento mais preciso tornaram necessária uma separação mais nítida das ciências, assim como, por outro lado, o mecanismo mais intricado dos Estados tornou necessária uma delimitação mais rigorosa dos estamentos e dos negócios, rompeu-se a unidade interior da natureza humana e uma luta funesta separou as suas forças harmoniosas. (...) A natureza de pólipo dos Estados gregos, onde cada indivíduo gozava uma vida independente e podia, quando necessário, elevar-se à totalidade, deu lugar a uma engenhosa engrenagem cuja vida mecânica, em sua totalidade, é formada pela composição de infinitas partículas sem vida. Divorciaram-se o Estado e a Igreja, as leis e os costumes; a fruição foi separada do trabalho; o meio, do fim; o esforço, da recompensa. Eternamente acorrentado a um pequeno fragmento do todo, o homem só pode formar-se enquanto fragmento (...)". ${ }^{63}$

O caminho da cisão e da fragmentação, tão danoso para o indivíduo, foi contudo socialmente necessário, pois "inexiste outra maneira de a espécie progredir". ${ }^{64} \mathrm{O}$ antagonismo das disposições naturais humanas é o meio de todo progresso cultural, mas não a sua meta. "Pode o homem ser destinado a negligenciar a si mesmo em vista de outro fim qualquer? Deveria a natureza, através de seus fins, roubar-nos uma perfeição que a razão, através dos seus, nos prescreve? É falso, portanto, afirmar que a formação das forças isoladas torna necessário o sacrifício de

\footnotetext{
${ }^{61} E E, 35-7$.

$62 E E, 39$.

${ }^{63} E E, 40-1$.

${ }^{64} E E, 43$.
}

73 | Pensando - Revista de Filosofia Vol. 8, № 16, 2017

ISSN 2178-843X 
sua totalidade; e mesmo que a lei da natureza se empenhe por isso, tem de depender de nós restabelecer em nossa natureza, através de uma arte mais elevada, essa totalidade que foi destruída pelo artifício." ${ }^{65}$

O que Schiller diz sobre os gregos, em contraste com os modernos, vale muito menos pelo seu valor como uma visão adequada do passado do que como uma imagem antecipatória de uma humanidade reconciliada consigo mesma. 0 restabelecimento da totalidade destruída é a tarefa histórica dos modernos, mas por uma nova configuração das forças liberadas e desenvolvidas pela fragmentação. A ferida aberta pela cultura terá de ser fechada por ela, embora não por obra do Estado ou de uma revolução. Uma transformação substancial da sociedade não terá lugar "até que seja de novo suprimida a cisão interior do homem e sua natureza se desenvolva o suficiente para ser, ela mesma, artista e capaz de assegurar realidade à criação política da razão. (...) O caráter da época, portanto, deve por um lado reerguer-se de sua profunda degradação, furtar-se à cega violência da natureza e, por outro, regressar à sua simplicidade, verdade e plenitude: uma tarefa para mais de um século." ${ }^{66}$

Nessa exigência aparentemente paradoxal - a cultura como emancipação da natureza e, ao mesmo tempo, como retorno a ela - o ceticismo diante da busca de soluções imediatas se expressa pela convicção de que apenas um longo trabalho formativo poderá criar as condições subjetivas - culturais - para a instituição da liberdade. Esse trabalho formativo é uma condição incontornável para o Estado da liberdade, rumo ao qual a Aufklärung teria representado apenas um primeiro passo, essencial, embora não suficiente. Schiller advoga uma radicalização da Aufklärung: o pacto obscurantista entre tutores e tutelados, repudiado por Kant, deve ser rompido não apenas pela extensão da "ilustração do entendimento" à formação caráter, mas também por um movimento pelo qual o entendimento seja tocado pelo coração: "A formação da sensibilidade é, portanto, a necessidade mais premente da época, não apenas porque ela vem a ser um meio de tornar o conhecimento melhorado eficaz

\footnotetext{
${ }^{65} E E, 45$.

$66 E E, 47-8$.
} 
para a vida, mas também porque desperta para a própria melhora do conhecimento." 67

O restabelecimento da totalidade - a emancipação da natureza e o retorno a ela como obra da liberdade - supõe assim a radicalização da Aufklärung como uma "formação da sensibilidade". "Mas não há aqui talvez um círculo?” pergunta Schiller. “Deve a cultura teórica propiciar a prática, e esta ser a condição daquela? Toda melhoria política deve partir do enobrecimento do caráter - mas como o caráter pode enobrecer-se sob a influência de uma constituição bárbara? Para esse fim seria preciso encontrar um instrumento que o Estado não fornece, e abrir fontes que se conservem límpidas e puras apesar de toda corrupção política." ${ }^{68}$

Eis aqui o problema com o qual se encerra a última carta da primeira série de Sobre a educação estética do homem publicada em janeiro de 1795 no fascículo de estréia de Die Horen: a determinação do instrumento e das fontes capazes de regenerar a cultura. "Cheguei ao ponto a que se dirigiam todas as minhas considerações precedentes", diz Schiller. "Este instrumento são as belas-artes; estas fontes nascem em seus modelos imortais." 69 O instrumento é a arte, mas Schiller não exclui a ciência, pois "ambas gozam de uma absoluta imunidade em face do arbítrio humano". ${ }^{70}$ Ambas estão enraizadas na estrutura transcendental da razão, mas a arte goza de uma prerrogativa: a da beleza como a força capaz de superar uma cultura cindida entre a selvageria e a barbárie, resgatando o homem desse "duplo desvio". ${ }^{71}$

As relações de Schiller com a filosofia de Kant são tão complexas quanto as de Fichte com o próprio Kant. E quando Schiller toma posição diante de Kant, faz o mesmo diante de Fichte e da posição desse diante de Kant, o que torna o problema ainda mais delicado. Contudo, Schiller certamente humanizou o conceito kantiano de liberdade, resgatando a dignidade da sensibilidade. Em outras palavras, ele

\footnotetext{
${ }^{67} E E, 51$.

${ }^{68} E E$, 53. Uma excelente análise do problema encontra-se em WILKINSON, E. M. e WILLOUGHBY, L. A. Schillers Ästhetische Erziehung des Menschen. Eine Einführung. Munique: Beck, 1967, pp. 82-4.

${ }^{69} E E, 53$.

${ }^{70} E E, 53$.

${ }^{71} E E, 57$.
} 
desbarbarizou o conceito de liberdade, reconciliando razão e sensibilidade pela "ação recíproca" entre os impulsos sensível e formal. Se, como disse Lichtenstein, Schiller quis "refutar Kant com meios kantianos", 72 tudo indica que, em nome do espírito da filosofia transcendental, ele também quis refutar Fichte com meios fichteanos, recorrendo assim à teoria dos impulsos e concebendo de um outro modo a ação recíproca desses impulsos. Como vimos, a tese central - formulada ao mesmo tempo em profunda sintonia e divergência com Fichte - é a de que a perfeita ação recíproca entre ambos os impulsos só é concebível para o homem como uma "tarefa da razão", pois trata-se da "Ideia de sua humanidade", que como tal é "um infinito", uma meta da qual podemos apenas nos aproximar sem jamais alcançá-la. ${ }^{73}$ No entanto, o medium privilegiado da reconciliação do homem consigo mesmo - e da modernidade cindida - não é a educação moral encarnada pelo representante exemplar da humanidade, o filósofo, como queria Fichte, mas sim a arte e o seu poder unificador da natureza humana. "Assim aparece nitidamente o caráter polêmico das Cartas sobre a educação estética", escreveu Léon, "assim se explica a linguagem nova que Schiller fala. Se ele se coloca sobre o terreno de Fichte, se ele se serve dos seus pontos de vista, se ele adota as expressões mesmas do autor da Doutrina da ciência, é afim de combatê-lo com mais segurança."74

Também aqui não há uma única evidência textual que justifique a caracterização das diferenças e divergências entre Schiller e Fichte como um combate, como um confronto de adversários. Objetivamente, o contato com Fichte e a assimilação da Wissenschaftslehre foram essenciais para que Schiller concebesse o que ele mesmo chamou o seu "System", a sua "Elementarphilosophie", desenvolvida à maneira de uma analítica antropológica metodologicamente inspirada por Fichte; e o primado da educação estética e do artista perante a educação moral e o filósofo também se justifica objetivamente como uma arraigada conviç̧ão de Schiller que alcançou sua expressão mais consistente no seu "idealismo estético", a forma final e

72 LICHTENSTEIN, E. "Schillers 'Briefe über die ästhetische Erziehung' zwischen Kant und Fichte". In: Archiv für Geschichte der Philosophie, 39, 1930, p. 106.

${ }^{73} E E, 77$.

${ }^{74}$ LÉON, Xavier. Fichte et son Temps, vol. 1, p. 349. 
mais original de sua contribuição para o estabelecimento do idealismo transcendental, tornada possível em boa medida pelo impulso de Fichte.

As cartas sobre a educação estética também se deixam ler como uma resposta a Fichte na medida em que buscam responder a uma questão que Kant deixara em aberto. Kant limitara sua crítica da faculdade do juízo estética ao exame do seu significado para a investigação transcendental, justificando assim a exclusão de problemas como o da "formação e cultura do gosto". ${ }^{75}$ Pedia ao leitor que fosse indulgente quanto a isso, mas rigoroso em face do que se propusera fazer. Por sua vez, Schiller não só retomou a investigação transcendental como procurou estendê-la àquele problema. Por um lado - e contra a convicção de Kant, segundo a qual é possível apenas uma crítica do gosto e não uma "ciência do belo", pois o gosto não seria "determinável por princípios"76 —, Schiller empenhou-se justamente na busca de um fundamento objetivo do belo e do gosto; por outro lado, procurou desenvolver a investigação transcendental a partir do ponto em que Kant a deixara, considerando os efeitos do gosto sobre a formação do homem e da sociedade, embora sob uma perspectiva de certo modo inversa, pois enquanto Kant acreditava que a "cultura do sentimento moral" seria a "verdadeira propedêutica para a fundação do gosto", ${ }^{77}$ Schiller via a cultura do gosto como o esteio para a fundação do sentimento moral. Ao assumir essa perspectiva, a educação estética é também objetivamente contraposta à educação moral advogada por Fichte como o recurso mais adequado para a promoção do que, de resto, tanto ele quanto Schiller julgavam fundamental: a promoção do acordo do homem consigo mesmo.

A polêmica entre os dois filósofos tornou-se explícita - ou começou efetivamente - quando Schiller recusou-se a publicar um trabalho de Fichte em Die Horen: "Sobre espírito e letra na filosofia. Numa série de cartas", pois o recebera como uma resposta inoportuna e equivocada ao que vinha publicando na mesma revista (também sob a forma de cartas...) sobre a educação estética. Documentada

\footnotetext{
75 KANT, Immanuel. Crítica da faculdade do juízo. Trad. Valério Rohden e António Marques. Rio de Janeiro: Forense Universitária, 1993, B 261.

${ }^{76}$ Ibid.

77 Ibid., B 264.
} 
pelo que restou da correspondência que ambos mantiveram entre junho e agosto de 1795, essa polêmica poderia ser analisada à luz do problema do diagnóstico e da crítica da modernidade. Creio que uma tal análise mostraria - e com isso me permito concluir com uma hipótese de trabalho - que, embora esse problema tenha sido apenas aflorado através de uma objeção de Fichte justamente à ideia de uma educação estética, ${ }^{78}$ ele é como que o núcleo "invisível" de toda a discussão, atraindo para a sua órbita todos as outras questões que dividiram Fichte e Schiller, como até mesmo a da forma de exposição dos textos filosóficos; ${ }^{79}$ pois na exigência da reconciliação do homem consigo mesmo, central para ambos, o que se deixa ver é a imagem da modernidade cindida e duas diferentes apostas: a de Fichte no poder pedagógico e regenerador da filosofia, do qual ele extrai consequências para a educação moral; e a de Schiller numa "educação para o gosto e a beleza", destinada a "desenvolver em máxima harmonia o todo de nossas faculdades sensíveis e espirituais". 80

\section{Referências bibliográficas}

BARBOSA, Ricardo. Schiller e a cultura estética. Rio de Janeiro: Jorge Zahar, 2004, 72 p.

BARBOSA, Ricardo. Limites do belo. Estudos sobre a estética de Friedrich Schiller. Belo Horizonte: Relicário, 2015, 191.

DÜSING, W. Friedrich Schiller. Über die ästhetische Erziehung des Menschen in einer Reihe von Briefen. Text, Materialien, Kommentar. Munique: Hanser, 1981, 355 p.

\footnotetext{
${ }^{78}$ Para Fichte, a liberdade era uma conquista do domínio humano sobre a natureza; e somente sob tais condições uma cultura do gosto seria possível. "É por isso que as épocas e os países da servidão são ao mesmo tempo os da falta de gosto; e se, por um lado, não é aconselhável deixar os homens livres antes que o seu sentido estético tenha se desenvolvido, por outro lado é impossível desenvolvê-lo antes que sejam livres; e a ideia de elevar os homens mediante a educação estética à dignidade da liberdade, e com ela à liberdade mesma, nos leva a um círculo se não encontramos previamente um meio de despertar nos indivíduos da grande massa a coragem de não ser senhores nem escravos de ninguém." FICHTE, Johann Gottlieb. "Über Geist und Buchstab in der Philosophie. In einer Reihe von Briefe". In: J. G. Fichte-Gesamtausgabe der Bayerischen Akademie der Wissenschaften, I/6: Werke 1799-1801. Edição de Reinhard Lauth e Hans Jacob, com a colaboração de Erich Fuchs, Kurt Hiller e Peter K. Schneider. Stuttgart: Frommann-Holzboog, 1981, p. 348. Cf. tb. HOGREBE, W. "Schiller und Fichte. Eine Skizze", pp. 283-6.

79 Sobre essa questão cf. BARBOSA, Ricardo. "Verdade e beleza. Schiller e o problema da escrita filosófica". In: idem, Limites do belo. Estudos sobre a estética de Friedrich Schiller, pp. 77-117.

${ }^{80} E E, 107$, nota.
} 
FICHTE, Johann Gottlieb. O destino do erudito. Tradução e posfácio de Ricardo Barbosa. São Paulo Hedra, 2014, 129 p.

FICHTE, Johann Gottlieb. "Über Geist und Buchstab in der Philosophie. In einer Reihe von Briefe". In: Gesamtausgabe der Bayerischen Akademie der Wissenschaften (GA) I/6: Werke 1799-1801.Stuttgart: Frommann-Holzboog, 1981, p. 333-361.

HAMBURGER, K.. "Schillers ästhetisches Denken". In: SCHILLER, Friedrich. Über die ästhetische Erziehung des Menschen. Stuttgart: Reclam, 1997, p. 131-150.

HOGREBE, W. "Schiller und Fichte. Eine Skizze". In: BOLTEN, J. (org.), Schiller Briefe über die ästhetische Erziehung des Menschen. Frankfurt am Main: Suhrkamp, 1984, p. 276-89.

KANT, Immanuel. Crítica da faculdade do juízo. Trad. Valério Rohden e António Marques. Rio de Janeiro: Forense Universitária, 1993, 381 p.

LÉON, Xavier. "Schiller et Fichte". In: C. SCHMIDT et al. Études sur Schiller. Paris: F. Alcan, 1905, p. 41-93.

LÉON, Xavier. Fichte et son Temps. Vol. 1. Paris: Armand Colin, 1922, 676 p.

LICHTENSTEIN, E. "Schillers 'Briefe über die ästhetische Erziehung' zwischen Kant und Fichte". In: Archiv für Geschichte der Philosophie, 39, 1930, p. 102-44, 274-94.

SCHILLER, Friedrich. Schillers Werke. Nationalausgabe. 26. Bd:. Briefwechsel: Schillers Briefe 1. 3. 1790 - 17. 5. 1794. Weimar: Hermann Böhlaus Nachfolger, 1992, 963 p.

SCHILLER, Friedrich. Schillers Werke. Nationalausgabe. 27. Bd.: Briefwechsel: Schillers Briefe 1794-1795. Weimar: Hermann Böhlaus Nachfolger, 1958, 418 p.

SCHILLER, Friedrich. Cultura estética e liberdade. Cartas ao Príncipe de Augustenburg, fevereiro-dezembro de 1793. Organização, tradução e introdução de Ricardo Barbosa. São Paulo: Hedra, 2009, 172 p.

SCHILLER, Friedrich. A educação estética do homem. Numa série de cartas. Trad. Roberto Schwarz e Márcio Suzuki. São Paulo: Iluminuras, 1990, 162 p.

SCHILLER, Friedrich. Poesia ingênua e sentimental. Trad. Márcio Suzuki. São Paulo. lluminuras, 1991, $150 \mathrm{p}$.

SZONDI, Peter. Antike und Moderne in der Ästhetik der Goethezeit. In: idem, Poetik und Geschichtsphilosophie I. Frankfurt am Main: Suhrkamp, 1974, p. 11-265.

WILKINSON, Elizabeth Mary e WILLOUGHBY, Leonard Ashley. 1967. Schillers Ästhetische Erziehung des Menschen. Eine Einführung. Munique: Beck, 312 p. 